\title{
Antiplasmodial hirsutinolides from Vernonia staehelinoides and their utilization towards a simplified pharmacophore
}

\author{
Pamisha Pillay $^{\mathrm{a}}$, Robert Vleggaar ${ }^{\mathrm{b}}$, Vinesh J. Maharaj ${ }^{\mathrm{a}}$, Peter J. Smith ${ }^{\mathrm{c}}$, Carmen A. \\ Lateganc, Frank Chouteau $^{\mathrm{d}}$ and Kelly Chibale ${ }^{\mathrm{d}, \mathrm{e}}$ \\ ${ }^{a}$ Biosciences, CSIR, RSA, P.O. Box 395, Pretoria 0001, South Africa \\ ${ }^{b}$ Department of Chemistry, University of Pretoria, Pretoria 0002, South Africa \\ ${ }^{c}$ Division of Pharmacology, University of Cape Town, Observatory, 7925, South Africa \\ ${ }^{\mathrm{d}}$ Department of Chemistry, University of Cape Town, Rondebosch 7701, South Africa \\ ${ }^{\mathrm{e}}$ Institute of Infectious Disease and Molecular Medicine, University of Cape Town, \\ Rondebosch 7701, South Africa
}

\section{Abstract}

The dichloromethane extract of the leaves of Vernonia staehelinoides Harv. (Asteraceae) showed in vitro activity ( $\mathrm{IC}_{50} \sim 3 \mu \mathrm{g} / \mathrm{ml}$ ) against the chloroquine-sensitive (D10) and the chloroquine-resistant (K1) strains of Plasmodium falciparum. Through conventional chromatographic techniques and bioassay-guided fractionation two structurally-related hirsutinolides displaying in vitro antiplasmodial activity ( $\mathrm{IC}_{50} \sim 0.2 \mu \mathrm{g} / \mathrm{ml}$ against D10) were isolated and identified by spectroscopic data. Compounds 1, $8 \alpha-(2-$

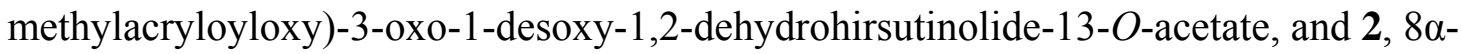
(5'-acetoxysenecioyloxy)-3-oxo-1-desoxy-1,2-dehydrohirsutinolide-13-O-acetate were found to be cytotoxic to mammalian Chinese Hamster Ovarian (CHO) cells at similar concentrations but proved to be attractive scaffolds for structure-activity relationship studies. Two main privileged substructures, a $2(5 H)$-furanone unit and a dihydrofuran-4one unit, were identified as potential pharmacophores which may be responsible for the observed biological activity. Mucochloric and mucobromic acids were selected as 
appropriate 2(5H)-furanone substructures and these were shown to have comparable activity against the $\mathrm{D} 10$ and superior activity against the $\mathrm{K} 1$ strains relative to the hirsutinolide natural product. Mucochloric and mucobromic acids also show selective cytotoxicity to the malaria parasites compared to mammalian (CHO) cells in vitro. The antiplasmodial data obtained in respect of these two acids suggests that the $2(5 H)$ furanone substructure is a key pharmacophore in the observed antiplasmodial activity.

\section{Graphical abstract}

Bioassay-guided fractionation of the dichloromethane extract of the leaves of Vernonia staehelinoides led to the isolation of two structurally-related hirsutinolides, displaying in vitro antiplasmodial activity. The compounds lacked selectivity (cytotoxicity $v s$. bioactivity) but the results led to the identification of mucochloric and mucobromic acids as privileged $2(5 H)$-furanone substructures.

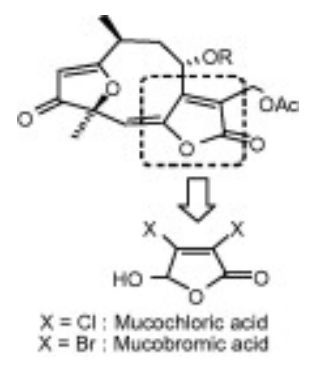

\section{Article Outline}

1. Introduction

2. Results and discussion

2.1. Identification of the active ingredients

2.2. Biological activity

2.3. Pharmacophore identification

3. Concluding remarks

4. Experimental

4.1. General experimental procedures

4.2. Plant material

\subsection{Extraction and isolation}


4.3.1. 8 $\alpha$-(2-Methylacryloyloxy)-3-oxo-1-desoxy-1,2-dehydrohirsutinolide-13-O-acetate (1)

4.3.2. 8 $\alpha$-(5'-Acetoxysenecioyloxy)-3-oxo-1-desoxy-1,2-dehydro-hirsutinolide-13-Oacetate (2)

4.4. Biological activity

4.4.1. Antiplasmodial assaying

4.4.2. Cytotoxicity assaying

Acknowledgements

References

\section{Introduction}

Malaria is recognised as one of the leading public health problems in sub-Saharan Africa. The evolution and spread of drug-resistant forms of the causative agent Plasmodium falciparum and the limited number of chemotherapeutic agents available to treat and control the disease has highlighted the need for new chemically diverse, effective drugs. Historically, plants have provided a major source of antimalarial agents and novel template compounds (Schwikkard and van Heerden, 2002).

Vernonia staehelinoides Harv. (Asteraceae), was identified as a potential source of new antimalarial drugs through a national multidisciplinary-consortium project aimed at scientifically validating South African medicinal plants for the treatment of malaria (Clarkson et al., 2004). Vernonia staehelinoides is indigenous to South Africa and is commonly known as "blouteebossie". It is a multi-stemmed perennial shrublet with stems and leaves covered with numerous short hairs, giving it a greyish appearance. Leaves are very narrow and long flexuous stems give rise to numerous flower heads.

$V$. staehelinoides is reported to be used medicinally but no details have been specified (Watt and Breyer-Brandwyk, 1962). Previous phytochemical investigations of this plant revealed that the roots contain squalene, stigmasterol and sitosterol while the aerial parts afforded caryophyllene, $\alpha$-humulene, germacrene $\mathrm{D}$ and the novel glaucolide, $3 \beta$ hydroxy-stilpnotomentolide-8-O-(5-acetoxysenecioate) (Bohlmann et al., 1982a and Bohlmann et al., 1982b). 
The in vitro antiplasmodial activity of the dichloromethane extract of this plant warranted further investigation to identify the biologically active components. Bioassay guided fractionation identified hirsutinolides 1, $8 \alpha$-(2-methylacryloyloxy)-3-oxo-1-desoxy-1,2dehydrohirsutinolide-13-O-acetate (Bohlmann et al., 1983), and 2, 8 $\alpha-\left(5^{\prime}-\right.$ acetoxysenecioyloxy)-3-oxo-1-desoxy-1,2-dehydrohirsutinolide-13-O-acetate (Bohlmann et al., 1983 and Tully et al., 1987), (Fig. 1) as the active components. This paper reports on the isolation and biological activity of these compounds and their utilization towards identifying a novel simplified pharmacophore.
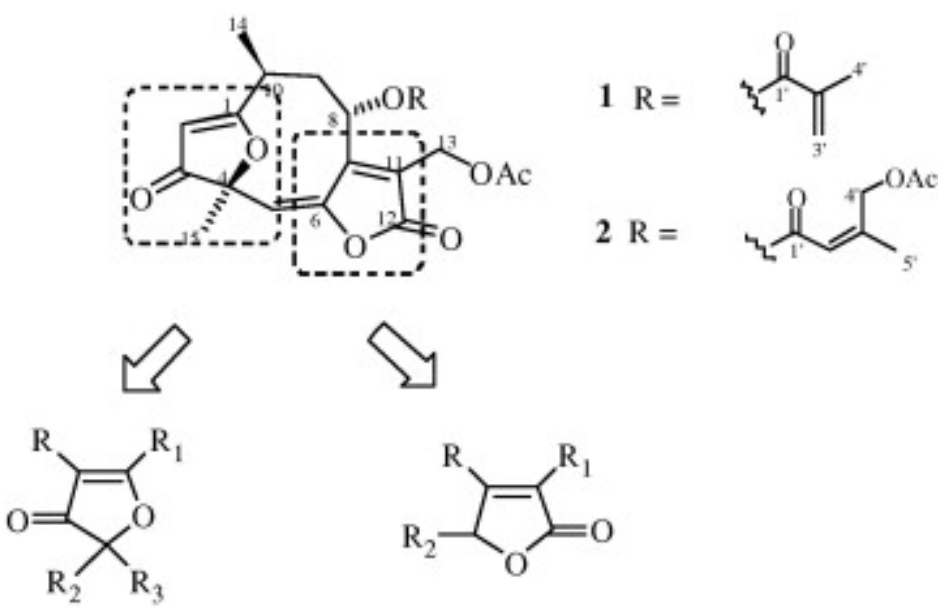<smiles>[R]C1=C([R])C([R])OC1=O</smiles>

Dihydrof uran-4-one

2(5H)-Furanone<smiles>[X]C1=C([X])C(O)OC1=O</smiles>

$\mathrm{X}=\mathrm{Cl}$ : Mucochloric acid

$\mathrm{X}=\mathrm{Br}:$ Mucobromic acid

Fig. 1. Structures of hirsutinolides $\mathbf{1}$ and $\mathbf{2}$, and the identified pharmacophores.

\section{Results and discussion}

\subsection{Identification of the active ingredients}

Dried, ground leaves of Vernonia staehelinoides were extracted sequentially with dichloromethane, dichloromethane/methanol (1:1) and water. The extracts were bioassayed in vitro against the chloroquine-sensitive D10 and the chloroquine-resistant 
K1 strains of Plasmodium falciparum. The dichloromethane and dichloromethane/methanol extracts were found to be active with $\mathrm{IC}_{50}$ values of 3.0 and $6.0 \mu \mathrm{g} / \mathrm{ml}$ against D10 and 2.8 and 4.5 against $\mathrm{K} 1$; respectively. The aqueous extract was relatively inactive $\left(\mathrm{IC}_{50}>10 \mu \mathrm{g} / \mathrm{ml}\right)$.

The dichloromethane extract was subjected to bioassay-guided fractionation using silica gel column chromatography and antiplasmodial activity against the D10 strain as the biological indicator. This resulted in the isolation and identification of hirsutinolides $\mathbf{1}$ and 2 as the active ingredients. Bioassay-guided fractionation of the 1:1 dichloromethane/methanol extract led to the same active ingredients. The structures of compounds $\mathbf{1}$ and $\mathbf{2}$ were elucidated using spectroscopic techniques. The two ketohirsutinolides differed only in the ester groups at the C-8 position, with compound $\mathbf{1}$ containing a 2-methylpropenoyl moiety and compound $\mathbf{2}$ having a 4acetoxy-3-methyl-2Z-butenoyl group. The $Z$ configuration of the 2 ' double bond in hirsutinolide 2 followed from the strong NOE observed between $\mathrm{H}-2^{\prime}$ and $\mathrm{H}-5^{\prime}$. This was confirmed by comparison of the H-4' chemical shift $\left(\delta_{\mathrm{H}} 5.17\right)$ (Table 1$)$ with published data for methyl $Z$ - and $E$-4-acetoxy-3-methyl-2-butenoates: the $Z-\mathrm{CH}_{2}$ signals were shown to occur at $\delta_{\mathrm{H}} 5.15$, whereas the $E-\mathrm{CH}_{2}$ signals were observed at $\delta_{\mathrm{H}} 4.56$ (Tully et al., 1987). The structures of the compounds were confirmed by comparison with ${ }^{1} \mathrm{H}$ NMR data reported in the literature (Bohlmann et al., 1983). This comparison did reveal that the original reporters had transposed the H-13 and H-4' resonances of compound 2. In this account an unequivocal assignment of these resonances based on 2D NMR data, which the original reporters did not have access to, is reported (Table 1). The ${ }^{13} \mathrm{C}$ data of compounds $\mathbf{1}$ and $\mathbf{2}$ are also reported in Table 1. 
Table 1.

${ }^{1} \mathrm{H}$ and ${ }^{13} \mathrm{C}$ NMR data $\left(399.96 \mathrm{MHz}\right.$, in $\mathrm{CDCl}_{3}$ ) for hirsutinolides $\mathbf{1}$ and $\mathbf{2}$

\begin{tabular}{|c|c|c|c|c|}
\hline \multirow[t]{2}{*}{ Position } & \multicolumn{2}{|l|}{1} & \multicolumn{2}{|l|}{2} \\
\hline & $\delta_{\mathrm{C}}$ & $\delta_{\mathrm{H}}$ (mult., $J$ in $\mathrm{Hz}$ ) & $\delta_{\mathrm{C}}$ & $\delta_{\mathrm{H}}$ (mult., $J$ in Hz) \\
\hline 1 & 194.9 & - & 194.9 & - \\
\hline 2 & 98.3 & $5.40(s)$ & 99.9 & $5.43(s)$ \\
\hline 3 & 202.3 & - & 202.2 & - \\
\hline 4 & 86.9 & - & 86.9 & - \\
\hline 5 & 117.9 & $5.89(s)$ & 117.4 & $5.88(s)$ \\
\hline 6 & 146.2 & - & 146.2 & - \\
\hline 7 & 151.1 & - & 151.2 & - \\
\hline 8 & 65.7 & $6.45(\operatorname{br} d, 9.0)$ & 65.6 & $6.23(\operatorname{br} d, 8.0)$ \\
\hline $9 \mathrm{a}$ & 40.2 & $2.77(d d d, 5.1,9.0,14.9)$ & 40.1 & $2.75(d d d, 5.5,8.0,14.7)$ \\
\hline $9 b$ & & $1.70(d d, 11.0,14.9)$ & & $1.70(d d, 9.0,7.0)$ \\
\hline 10 & 31.3 & $3.01(d d q, 5.1,11.0,7.0)$ & 31.9 & $3.01(d d q, 5.5,9.0,7.0)$ \\
\hline 11 & 132.7 & - & 131.8 & - \\
\hline 12 & 166.1 & - & 166.2 & - \\
\hline $13 \mathrm{a}$ & 55.7 & $4.91(d, 13.2)$ & 55.8 & $4.93(d, 13.1)$ \\
\hline $13 b$ & & $5.09(d, 13.2)$ & & $5.02(d, 13.1)$ \\
\hline 14 & 15.5 & $1.26(d, 7.0)$ & 15.4 & $1.25(d, 7.0)$ \\
\hline 15 & 20.7 & $1.58(s)$ & 20.6 & $1.59(s)$ \\
\hline $1^{\prime}$ & 166.9 & - & 164.0 & - \\
\hline $2^{\prime}$ & 135.7 & - & 116.5 & $5.75\left(\right.$ br $\left.m^{\underline{\mathbf{a}}}\right)$ \\
\hline $3{ }^{\prime} \mathrm{a}$ & 127.0 & $5.63(d q, 1.6,1.6)$ & 156.8 & - \\
\hline $3^{\prime} \mathrm{b}$ & & $6.22($ br $d q, 1.6,1.0)$ & & \\
\hline
\end{tabular}




\begin{tabular}{|c|c|c|c|c|}
\hline \multirow[t]{2}{*}{ Position } & \multicolumn{2}{|l|}{1} & \multicolumn{2}{|l|}{2} \\
\hline & $\delta_{\mathrm{C}}$ & $\delta_{\mathrm{H}}$ (mult., $J$ in $\mathrm{Hz}$ ) & $\delta_{\mathrm{C}}$ & $\delta_{\mathrm{H}}$ (mult., $J$ in $\mathrm{Hz}$ ) \\
\hline $4^{\prime} \mathrm{a}$ & 18.1 & $1.93(d d, 1.6,1.0)$ & 63.6 & $5.12\left(\mathrm{br} d m^{\mathrm{a}}, 15.5\right)$ \\
\hline $4^{\prime} \mathrm{b}$ & & & & $5.22\left(\mathrm{br} d m^{\mathrm{a}}, 15.5\right)$ \\
\hline $5^{\prime}$ & - & - & 21.5 & $1.91\left(\mathrm{br} \mathrm{m}^{\mathrm{a}}\right)$ \\
\hline $13-\mathrm{O}-\mathrm{COCH}_{3}$ & 170.2 & - & 170.2 & - \\
\hline $13-\mathrm{O}-\mathrm{COCH}_{3}$ & 20.7 & $2.03(s)$ & 20.7 & $2.03(s)$ \\
\hline $4^{\prime}-\mathrm{O}-\mathrm{COCH}_{3}$ & - & - & 170.6 & - \\
\hline $4^{\prime}-\mathrm{O}-\mathrm{COCH}_{3}$ & - & - & 20.7 & $2.05(s)$ \\
\hline
\end{tabular}

${ }^{\text {a }}$ Allylic coupling of $\sim 1 \mathrm{~Hz}$.

It has been suggested that hirsutinolides are not natural products but are rather artefacts formed from glaucolides on exposure to slightly acidic silica gel during chromatography (Borkosky et al., 1997 and Tully et al., 1987). However, compounds 1 and 2 were easily detected on TLC through their characteristic colours (orange and brown, respectively, with vanillin) and $R_{\mathrm{f}}$ values ( 0.29 and 0.23 , respectively with actetone-hexanedichloromethane 1:4.5:4.5) prior to any silica gel chromatography suggesting that these may not be artefacts; unless the acid-catalyzed rearrangement could have been effected during the TLC analysis, itself.

Although compounds $\mathbf{1}$ and $\mathbf{2}$ have been isolated previously from other South African Vernonia species (Bohlmann et al., 1983 and Tully et al., 1987) this is the first report on the isolation of these compounds from $V$. staehelinoides.

\subsection{Biological activity}

There are no previous reports of compounds $\mathbf{1}$ and $\mathbf{2}$ being investigated for any biological activity. In this account the compounds are demonstrated to have significant in vitro antiplasmodial activity against the $\mathrm{D} 10$ strain of $P$. falciparum. The difference in their $\mathrm{C}$ 8 ester groups does not appear to significantly influence the observed antiplasmodial activities of compounds $\mathbf{1}$ and $\mathbf{2}$ as they were equipotent against the chloroquine-sensitive 
(D10) strain. There was a marginal difference in their observed activity against the chloroquine-resistant strain (Table 2).

Table 2.

In vitro antiplasmodial activity, cytotoxicity and selectivity index (SI) values for chloroquine, emetine, hirsutinolides 1 and 2, and mucochloric and mucobromic acids

\begin{tabular}{|l|l|l|l|l|}
\hline Compound & $\left.\mathbf{D 1 0}, \mathbf{I C}_{\mathbf{5 0}} \mathbf{( n g} / \mathbf{m l}\right)$ & $\left.\mathbf{K 1}, \mathbf{I C}_{\mathbf{5 0}} \mathbf{( n g} / \mathbf{m l}\right)$ & $\mathbf{C H O}, \mathbf{I C}_{\mathbf{5 0}}(\boldsymbol{\mu g} / \mathbf{m l})$ & $\mathbf{S I}^{\mathbf{a}}$ \\
\hline Chloroquine & 12 & 182 & 18.5 & 1542 \\
\hline $\mathbf{1}$ & 260 & 1800 & 2.9 & 11 \\
\hline $\mathbf{2}$ & 240 & 2600 & 0.9 & 4 \\
\hline Mucochloric acid & 152 & 137 & 4.8 & 32 \\
\hline Mucobromic acid & 422 & 359 & 6.3 & 15 \\
\hline Emetine & - & - & 0.06 & - \\
\hline
\end{tabular}

${ }^{a}$ SI, cytotoxicity $\mathrm{CHO} \mathrm{IC}$ 50/antiplasmodial $\mathrm{D}_{10} \mathrm{IC}_{50}$.

In order to determine the specificity of the antiplasmodial activity of the hirsutinolides, it was considered necessary to obtain information about their general cytotoxicity. For this, the compounds were tested for cytotoxicity against a Chinese Hamster Ovarian (CHO) cell line, using the microculture tetrazolium (MTT) assay and Emetine as a positive control (Table 2).

The selectivity index (SI) value for compound $\mathbf{1}$ (Table 2) indicates that it is approximately 11 times more potent to the parasites than to mammalian cells. For compound 2 this ratio is of the order of 4, indicating less selectivity. In considering a recent publication (Pink et al., 2005) outlining criteria for antiparasitic drug discovery, a compound can be considered a hit if it is:

- Active in vitro against whole protozoa with an $\mathrm{IC}_{50}$ of $\leqslant 1 \mu \mathrm{g} / \mathrm{ml}$.

- Selective (at least 10-fold more active against the parasite than against a mammalian cell line).

Based on these criteria, only compound 1 can be considered a hit while compound $\mathbf{2}$ was not selective enough to kill the parasites without damaging mammalian cells. 


\subsection{Pharmacophore identification}

Overall, the active components of $V$. staehelinoides may not be considered as viable antimalarial drug leads as their activity does not compare to that of standard clinically used drugs such as chloroquine. Moreover, compound $\mathbf{2}$ is non-selective while compound 1 shows only limited selectivity. The hirsutinolides do, however, provide attractive new scaffolds for chemical modification with the view of exploring structure-activity relationships. This could be achieved via one or more of the following three approaches namely;

(i) modification of core structures, depending on the availability of appropriate quantities of the hirsutinolides from natural sources;

(ii) total synthesis from readily available and/or accessible starting materials. A synthesis and/or semi-synthesis plan amenable to chemical library generation could then be planned and subsequently implemented;

(iii) synthesis of derivatives around the basic structure of privileged sub-structures identified from the hirsutinolides.

Of the three aforementioned approaches, the last approach was considered to be the most attractive within the context of the hirsutinolides. These natural products have two main privileged substructures which may be the pharmacophores responsible for the observed antiplasmodial activity of the hirsutinolides: a 2(5H)-furanone unit and a dihydrofuran-4one unit as shown in Fig. 1. These substructures are known to possess varying biological activities. The $2(5 H)$-furanone moiety occurs in many natural products that exhibit biological activities ranging from antibiotic (Miao and Andersen, 1991 and Davidson and Ireland, 1990), cytotoxic (Ortega et al., 2000, Bohlmann et al., 1982a and Bohlmann et al., 1982b) and antitumor properties (Hung et al., 1990) to inhibition of cholesterol biosynthesis (Kuhnt et al., 1990). On the other hand the dihydrofuran-4-one moiety is known for its antitumoral activity (Smith et al., 1981, Kupchan et al., 1976 and LeQuesne et al., 1978).

In order to verify the aforementioned pharmacophore hypothesis, appropriate privileged furanone substructures were identified and evaluated for antiplasmodial activity. Acifran, which contains a dihydrofuran-4-one unit, was found to have no antiplasmodial activity 
at a concentration of $1.0 \mu \mathrm{g} / \mathrm{ml}$ disputing the possibility that the dihydrofuranone moiety is a key pharmacophore in the observed antiplasmodial activity of the hirsutinolides. Mucochloric and mucobromic acids were initially identified as appropriate privileged 2(5H)-furanone substructures (Fig. 1). Relative to the "lead" hirsutinolide natural products, compounds $\mathbf{1}$ and $\mathbf{2}$, these significantly simplified structures (mucochloric and mucobromic acids) show comparable activity against D10 and superior activity against K1 strains of P. falciparum (Table 2). Furthermore, mucochloric and mucobromic acids are equally active in D10 and $\mathrm{K} 1$ strains of $P$. falciparum. This equipotency suggests that chloroquine cross-resistance is not observed with mucochloric and mucobromic acids. For such significantly simplified structures compared to the rather complex hirsutinolide natural product, the in vitro data are noteworthy. Besides, they show selective cytotoxicity to the malaria parasites compared to mammalian cells (CHO) in vitro with selectivity indices of 32 and 15 , respectively (Table 2).

\section{Concluding remarks}

The identification of antiplasmodial hirsutinolides from $V$. staehelinoides suggests that they may play a role in the medicinal properties of the plant, but their potential for the development of antimalarial drugs is limited due to inherent cytotoxicity and lack of selectivity. The results did however lead to the identification of potential pharmacophores, a $2(5 H)$-furanone unit and a dihydrofuran-4-one unit. The antiplasmodial data obtained in respect of mucochloric and mucobromic suggests that the $2(5 H)$-furanone is at least one of the key pharmacophores responsible for the observed antiplasmodial activity.

\section{Experimental}

\subsection{General experimental procedures}

Mass spectra were recorded on a VG 70SEQ HRMS instrument, in the positive EI mode with a resolution of 7500 at $8 \mathrm{kV}$. Nuclear magnetic resonance spectra were recorded on a Varian $400 \mathrm{MHz}$ Unity spectrophotometer in $\left[{ }^{2} \mathrm{H}\right]$-chloroform with TMS as internal 
standard. Optical rotations were measured in chloroform at room temperature on a Perkin-Elmer 241 polarimeter at $589 \mathrm{~nm}$ (Na D-line) using a $1 \mathrm{dm}$ cell.

The fractionation process involved column and thin layer chromatographic techniques. Different sized columns, ranging from 1.5 to $6 \mathrm{~cm}$ in diameter, were used depending on the amount of sample and the purification stage. Silica gel column chromatography was conducted using silica gel $60(0.063-0.2 \mathrm{~mm})$ and flash silica gel chromatography was carried out using 35-75 $\mu \mathrm{m}$ flash silica gel (Merck Art). Solvents used in chromatography were of technical grade and were distilled before use. TLC analysis was conducted on $0.20 \mathrm{~mm}$ pre-coated (SIL-25 UV254) glass-backed plates using acetonehexane-dichloromethane (1:4.5:4.5). The plates were developed using a vanillinconcentrated $\mathrm{H}_{2} \mathrm{SO}_{4}(1 \mathrm{~g} / 100 \mathrm{ml})$ spray reagent and then heated. Mucobromic acid (racemic) and mucochloric acid (racemic) were purchased from Sigma-Aldrich and used as received.

\subsection{Plant material}

Vernonia staehelinoides Harv. plant material was collected in April 1999 in the Magaliesburg region of the Gauteng province in South Africa. Voucher specimen (EN00323) containing flowers and aerial parts of the plants were identified and retained at the National Herbarium (Pretoria). Plant material was dried in an oven at $45^{\circ} \mathrm{C}$ for $48 \mathrm{~h}$ and stored at room temperature until processing.

\subsection{Extraction and isolation}

Dried plant material (120 g) was finely ground and extracted with dichloromethane (1 11$)$ at room temperature for $4 \mathrm{~h}$ with occasional stirring. The solvent was evaporated under reduced pressure to yield over $4 \mathrm{~g}(3.3 \%)$ of crude extract of which $1.5 \mathrm{~g}$ was subjected to open column chromatography over silica gel using a gradient eluent of increasing polarity (ethyl acetate-hexane 1:9 $\rightarrow$ ethyl acetate-hexane 3:2). Fractions were pooled according to their behaviour ( $R_{\mathrm{f}}$ values) on TLC. Six fractions in total were subsequently bioassayed against $P$. falciparum D10. Three of these showed improved antiplasmodial activity (D10 $\mathrm{IC}_{50}$ values $1.6,1.0$ and $0.9 \mu \mathrm{g} / \mathrm{ml}$ ) relative to the crude extract (D10 $\mathrm{IC}_{50}$ $3.0 \mu \mathrm{g} / \mathrm{ml})$. 
Using in vitro antiplasmodial activity against the $\mathrm{D} 10 P$. falciparum strain as the biological indicator, the active fractions were subjected to repeated flash chromatography and column chromatography to identify the active compounds. The bioassay-guided fractionation process yielded compounds 1 (Bohlmann et al., 1983) and 2 (Bohlmann et al., 1983 and Tully et al., 1987). The compounds were identified using spectral data such as ${ }^{1} \mathrm{H},{ }^{13} \mathrm{C}$, DEPT, HSQC, HMBC, COSY and NOESY NMR spectra, as well as EI-MS spectra, and by direct comparison with published spectral data and structures (Bohlmann et al., 1983).

4.3.1. 8 $\alpha$-(2-Methylacryloyloxy)-3-oxo-1-desoxy-1,2-dehydrohirsutinolide-13-O-acetate (1)

Colourless gum; $[\alpha]_{\mathrm{D}}-77.4\left(c 0.31, \mathrm{CHCl}_{3}\right) ;{ }^{1} \mathrm{H}$ and ${ }^{13} \mathrm{C} \mathrm{NMR}\left(\mathrm{CDCl}_{3}\right)$ data in Table 1; EI-MS (positive-ion mode) $m / z$ : $316.0868\left[\mathrm{M}-\mathrm{C}_{3} \mathrm{H}_{5} \mathrm{COOH}\right]^{+}$(calcd for $\mathrm{C}_{17} \mathrm{H}_{16} \mathrm{O}_{6}$ : 316.0947).

4.3.2. 8a-(5'-Acetoxysenecioyloxy)-3-oxo-1-desoxy-1,2-dehydro-hirsutinolide-13-Oacetate (2)

Colourless gum; $[\alpha]_{\mathrm{D}}-209.8\left(\mathrm{c} 0.51, \mathrm{CHCl}_{3}\right) ;{ }^{1} \mathrm{H}$ and ${ }^{13} \mathrm{C}$ NMR $\left(\mathrm{CDCl}_{3}\right)$ data in Table 1; EI-MS (positive-ion mode) $m / z$ : $316.0885\left[\mathrm{M}^{-} \mathrm{C}_{7} \mathrm{H}_{10} \mathrm{O}_{4}\right]^{+}$(calcd for $\mathrm{C}_{17} \mathrm{H}_{16} \mathrm{O}_{6}, 316.0947$ ).

\subsection{Biological activity}

\subsubsection{Antiplasmodial assaying}

Parasite viability was measured using parasite lactate dehydrogenase (pLDH) activity according to the methods described by Makler et al., 1995 and Clarkson et al., 2003. The chloroquine-sensitive (D10) and chloroquine-resistant (K1) strains of Plasmodium falciparum were continuously cultured according to the methods described by Trager and Jensen (1976). Fractions and pure compounds were dissolved in 10\% methanol and were further diluted in complete medium on the day of the experiment. The starting concentration for a full dose-response was $100 \mu \mathrm{g} / \mathrm{ml}$, which was diluted 2-fold in complete medium to give 10 concentrations, with the lowest concentration being $0.195 \mu \mathrm{g} / \mathrm{ml}$. The $\mathrm{IC}_{50}$ values were obtained from the dose response curves, using nonlinear dose-response curve fitting analyses with GraphPad Prism v. 4.00 software. 


\subsubsection{Cytotoxicity assaying}

Compounds were tested for in vitro cytotoxicity against a Chinese Hamster Ovarian (CHO) cell line using the 3-(4,5-dimethylthiazol-2-yl)-2,5-diphenyltetrazolium bromide (MTT) assay (Mosmann, 1983). Samples were dissolved in methanol:water (1:9). Stock solutions $(2 \mathrm{mg} / \mathrm{ml})$ were prepared and were stored at $-20{ }^{\circ} \mathrm{C}$ until use. The highest concentration of methanol to which the cells were exposed to had no measurable effect on the cell viability. Emetine was used as the positive control in all cases. The initial concentration of emetine was $100 \mu \mathrm{g} / \mathrm{ml}$, which was serially diluted in complete medium with 10 -fold dilutions to give six concentrations, the lowest being $0.001 \mu \mathrm{g} / \mathrm{ml}$. The same dilution technique was applied to all test samples with an initial concentration of $100 \mu \mathrm{g} / \mathrm{ml}$ to give five concentrations, with the lowest concentration being $0.01 \mu \mathrm{g} / \mathrm{ml}$. The concentration of test samples that inhibits $50 \%$ of the cells ( $\mathrm{IC}_{50}$ values) were obtained from dose-response curves, using a non-linear dose-response curve fitting analyses via GraphPad Prism v. 2.01 software.

\section{References}

Bohlmann et al., 1983 F. Bohlmann, N. Ates (Gören) and J. Jakupovic, Hirsutinolides from South African Vernonia species, Phytochemistry 22 (1983), pp. 1159-1162.

Bohlmann et al., 1982a F. Bohlmann, M. Wallmeyer and J. Jakupovic, Glaucolide from Vernonia staehelinoides, Phytochemistry 21 (1982), pp. 1445-1447.

Bohlmann et al., 1982b F. Bohlmann, C. Zdero, R.M. King and H. Robinson, Hirsutinolides and other sesquiterpene lactones from Vernonia species, Phytochemistry 21 (1982), pp. 695-699.

Borkosky et al., 1997 S. Borkosky, A. Bardón, C.A.N. Catalán, J.G. Díaz and W. Herz, Glaucolides, hirsutinolides and other sesquiterpene lactones from Vernonia pinguis, Phytochemistry 44 (1997), pp. 465-470.

Clarkson et al., 2003 C. Clarkson, W.E. Campbell and P. Smith, In vitro antiplasmodial activity of abietane and totarane diterpenes isolated from Harpagophytum procumbens (Devil's Claw), Planta Med. 8 (2003), pp. 720-724. 
Clarkson et al., 2004 C. Clarkson, V.J. Maharaj, N.R. Crouch, O.M. Grace, P. Pillay, M.G. Matsabisa, N. Bhagwandhin, P.J. Smith and P.I. Folb, In vitro antiplasmodial activity of medicinal plants native to or naturalized in South Africa, J. Ethnopharmacol. 92 (2004), pp. 177-191.

Davidson and Ireland, 1990 B.S. Davidson and C.M. Ireland, Lissoclinolide A polyketide lactone from Lissoclinum patella, J. Nat.Prod. 53 (1990), pp. 1036-1038.

Hung et al., 1990 J.H. Hung, S. Pummangura, S. Chaichantipyuth, C. Patarapanich, P.E. Fanwick, C.J. Chang and J.L. McLaughlin, New bioactive heptenes from Melodorum fruticosum (Annonaceae), Tetrahedron 46 (1990), pp. 5043-5054.

Kuhnt et al., 1990 D. Kuhnt, T. Anke, H. Besl, M. Bross, R. Herrmann, U. Mocek, B. Steffan and W. Steglich, Antibiotics from basidiomycetes. XXXVII. New inhibitors of cholesterol biosynthesis from cultures of Xerula melanotricha Dorfelt, J. Antibiot. 43 (1990), pp. 1413-1420.

Kupchan et al., 1976 S.M. Kupchan, C.M. Sigel, M.J. Matz, C.J. Gilmore and R.F. Bryan, Structure and stereochemistry of jatrophone, a novel macrocyclic diterpenoid tumor inhibitor 132, J. Am. Chem. Soc. 98 (1976), pp. 2295-2300.

LeQuesne et al., 1978 P.W. LeQuesne, S.B. Levery, M.D. Menachery, T.F. Brennan and R.F. Raffauf, Antitumor plants. Part 6. Novel modified germacranolides and other constituents of Eremanthus elaeagnus Schultz-Bip (Compositae), J. Chem. Soc. Perkin Trans. 1 (1978), p. 1572.

Makler et al., 1995 M.T. Makler, J.M. Ries, J.A. Williams, J.E. Bancroft, R.C. Piper, B.L. Gibbons and R.C. Hinrichs, Parasite lactate dehydrogenase as an assay for Plasmodium falciparum drug sensitivity, Am. J. Trop. Med. Hyg. 48 (1995), pp. 739-741. Miao and Andersen, 1991 S. Miao and R.J. Andersen, Rubrolides A-H, metabolites of the colonial tunicate Riterella Rubra, J. Org. Chem. 56 (1991), pp. 6275-6280.

Mosmann, 1983 T. Mosmann, Rapid colorimetric assay for cellular growth and survival: application to proliferation and cytotoxicity assays, J. Immunol. Methods 65 (1983), pp. $55-63$.

Ortega et al., 2000 J.J. Ortega, E. Zubia, J.M. Ocana, S. Naranjo and J. Salva, New rubrolides from the ascidian Synoicum biochmanni, Tetrahedron 56 (2000), pp. 39633967. 
Pink et al., 2005 R. Pink, A. Hudson, M. Mouriès and M. Bendig, Opportunities and challenges in antiparasitic drug discovery, Nat. Rev. Drug Discov. 4 (2005), pp. 727-740. Smith et al., 1981 A.B. Smith III, P.A. Levenberg, P.L. Jerris, R.M. Scarborough Jr. and P.M. Wovkulich, Synthesis and reactions of simple 3(2H)-furanones, J. Am. Chem. Soc. 103 (1981), pp. 1501-1513.

Schwikkard and van Heerden, 2002 S. Schwikkard and F.R. van Heerden, Antimalarial activity of plant metabolites, Nat. Prod. Rep. 19 (2002), pp. 675-692.

Trager and Jensen, 1976 W. Trager and J.B. Jensen, Human malaria parasites in continuous culture, Science 193 (1976), pp. 673-675.

Tully et al., 1987 L.E. Tully, M.S. Carson and T.B.H. McMurray, A novel sesquiterpene lactone from Vernonia erinacea, Tetrahedron Lett. 28 (1987), pp. 5925-5928.

Watt and Breyer-Brandwyk, 1962 J.M. Watt and M.G. Breyer-Brandwyk, The Medicinal and Poisonous Plants of Southern and Eastern Africa, Livingston, London (1962) p. 254.

Corresponding author. Tel.: +27 12841 2215; fax: +27 128414790 . 